\title{
A eutanásia animal na visão de estudantes de Medicina Veterinária e Ciências Biológicas
}

\section{Euthanasia under the perspective of veterinary medicine and biological sciences students}

\author{
Maria Anastácia Manzano, ${ }^{\star}$ José Ricardo Pachaly, ${ }^{* *}$ Kalli Horn Majczak, ${ }^{*}$ Aristeu Vieira da Silva, ${ }^{* \star}$ Elza Maria Galvão Ciffoni ${ }^{\star \star \star}$
}

\begin{abstract}
Resumo
A eutanásia, morte provocada, sem dor ou sofrimento, apresenta enfoques diferentes em casos humanos e animais. No segundo caso, além de permitida, a eutanásia é indicada e regulamentada. Após presenciarem a eutanásia de um exemplar de onça-pintada (Panthera onca) em um zoológico, estudantes dos cursos de graduação em Medicina Veterinária e Ciências Biológicas expressaram suas opiniões sobre diferentes motivações de eutanásia. Os resultados mostram que quando a questão é a eutanásia piedosa, os estudantes dos dois cursos são favoráveis à prática, apresentando opiniões iguais. O mesmo não acontece quando questionados sobre eutanásia sanitária ou eutanásia para manejo. Nestes casos, os estudantes de Medicina Veterinária mostraram-se mais favoráveis que os de Ciências Biológicas. Essas posições foram discutidas à luz dos códigos de ética dos profissionais envolvidos na pesquisa.
\end{abstract}

Palavras-chave: eutanásia animal, estudantes, medicina veterinária, ciências biológicas.

\begin{abstract}
Euthanasia is defined as the act or practice of causing death painlessly and presents different perspectives in human and animal cases. In the second case, besides being allowed, euthanasia is indicated and regulated. After witnessing the euthanasia of a jaguar (Panthera onca) in a zoo, students of veterinary medicine and biological sciences expressed their opinions about different euthanasia motivations. The results show that when the subject is the merciful euthanasia, the students of the two courses are favorable to the practice, presenting the same opinions. The same doesn't happen when questioned on sanitary euthanasia or euthanasia for handling. In these cases the veterinary students were more favorable than the biological sciences ones. These positions were discussed under the scope of both professionals' ethics codes.
\end{abstract}

Keywords: animal euthanasia, students, veterinary medicine, biological sciences.

\section{Introdução}

Eutanásia é definida etimologicamente como "boa morte" e entendida como "o ato de proporcionar a morte sem dor ou sofrimento" (AVMA, 2001; HOUAISS, 2002). A eutanásia animal, ao contrário da eutanásia humana, é permitida e indicada quando o bem-estar animal estiver ameaçado, quando o animal constituir ameaça à saúde pública ou animal, e quando o animal for objeto de ensino ou pesquisa. Esta prática está regulamentada pela Resolução 714 do Conselho Federal de Medicina Veterinária, de 20 de junho de 2002, onde são esclarecidos as situações, os procedimentos e os métodos a serem utilizados (Conselho Federal de Medicina Veterinária, 2006).

Entende-se por bem-estar animal "um completo estado de saúde física e mental, onde o animal encontra-se em harmonia com seu meio ambiente" (Molento, 2003).
A relação do homem com os animais vem ganhando novas dimensões no mundo contemporâneo. Além de fonte de alimentos e força para o trabalho, os animais muitas vezes ocupam espaço dentro da família humana, como um de seus membros, sendo atribuído a eles um papel significativo na promoção do bem-estar físico e mental das pessoas. Segundo Franco e Seminotti (2004), está ocorrendo uma humanização do animal, com mudanças em padrões de consumo, e uma expansão do mercado de alimentos e acessórios para animais de estimação. Há necessidade de redefinição de condutas e atuações dos profissionais que trabalham com a interface homem-animal, como os médicos-veterinários.

Associada a essa nova perspectiva de relacionamento entre as espécies, além da convivência familiar, as questões de conservação da fauna também estão na pauta de discussões. Neste quesito, os zoológicos aparecem como importantes centros de pesquisa de espécies, em seus mais variados

* Curso de Ciências Biológicas, Universidade Paranaense, Praça Mascarenhas de Moraes, s/n, Umuarama, PR, CEP: 870502-210, anastacia@unipar.br

** Programa de Mestrado em Ciência Animal, Universidade Paranaense, Umuarama, PR, pachaly@uol.com.br, aristeu@unipar.br

*** Curso de Medicina Veterinária, Universidade Tuiuti do Paraná, Rua Sidney Antonio Rangel Santos, 238, Curitiba, PR, CEP: 80010-330, ecoffoni@bol.com.br 
aspectos, desde genéticos até etológicos, e dos ecossistemas aos quais pertencem (Auricchio, 1999).

A idéia deste trabalho surgiu a partir de uma viagem de estudantes dos cursos de Medicina Veterinária e Ciências Biológicas a um zoológico. Os estudantes foram surpreendidos pela necessidade de realização da eutanásia de uma onça-pintada (Panthera onca) durante a visita, com a participação do professor (médico-veterinário) responsável pelas turmas. Esta vivência permitiu o levantamento e a discussão de importantes questões médicas, bioéticas, de conservação ambiental e de atribuições profissionais, que permearam toda a viagem de volta e vários momentos durante as aulas de Medicina de Animais Selvagens, no curso de Medicina Veterinária, e Zoologia de Deuterostômios, no curso de Ciências Biológicas, ministradas pelo mesmo professor.

O objetivo do presente trabalho foi verificar se os estudantes de Medicina Veterinária e Ciências Biológicas que participaram da viagem de estudos são favoráveis ou não à eutanásia animal, e se há diferença de opiniões entre os indivíduos dos dois cursos pesquisados.

\section{Material e método}

Um grupo de estudantes composto por 74 estudantes do quinto ano de Medicina Veterinária e 108 estudantes do terceiro ano de Ciências Biológicas, realizou uma visita técnica a um zoológico, proporcionada pelas disciplinas de Medicina de Animais Selvagens, do curso de Medicina Veterinária, e Zoologia de Deuterostômios, do curso de Ciências Biológicas. $\mathrm{Na}$ oportunidade, além de acompanharem e participarem de atividades de captura, anestesia e manejo de diversos animais selvagens, os estudantes acompanharam a eutanásia de uma onça-pintada (Panthera onca).

A eutanásia foi julgada necessária por uma junta médica composta pelos médicos veterinários do zoológico e pelo professor responsável pela visita, justificando-se pelo fato do bem-estar daquele animal encontrar-se ameaçado, não podendo seu sofrimento ser aliviado por qualquer meio disponível. O procedimento foi conduzido por médico-veterinário competente, e realizado pelo método de aprofundamento letal de anestesia geral.

Ao retornar à sala de aula, os estudantes foram convidados a debater o fato vivenciado na viagem, e após esse debate responderam a um questionário onde se perguntava se eram favoráveis ou desfavoráveis a diferentes situações de eutanásia, após serem adequadamente esclarecidos sobre tais situações, as quais foram definidas como:

a) Eutanásia "piedosa", quando o animal é sabidamente incapacitado ou vítima de grande sofrimento (idade muito avançada, doenças degenerativas, doenças neoplásicas e traumatismos muito severos);

b) Eutanásia "sanitária", quando o animal é portador de uma enfermidade que represente risco para a saúde humana, como a tuberculose, por exemplo, procedimento obrigatório pelas leis brasileiras (BRASIL, 2004)

c) Eutanásia "para manejo", quando há animais excedentes, não ameaçados de extinção, sem condições de serem alojados de maneira que respeite as exigências mínimas de bem-estar, e sem condições de serem reintegrados à vida em liberdade na natureza.

Após a aplicação dos questionários os dados foram tabulados e realizou-se o teste Exato de Fischer na comparação das proporções de respostas favoráveis e desfavoráveis entre os estudantes dos cursos de Medicina Veterinária e Ciências Biológicas. As proporções de respostas favoráveis e desfavoráveis, para estudantes de um mesmo curso, foram comparadas pela estimação do intervalo de confiança a 95\% (Curi, 1998).

\section{Resultados e discussão}

Os resultados das comparações das proporções de respostas favoráveis e desfavoráveis às questões sobre eutanásia, entre estudantes dos cursos de Medicina Veterinária e Ciências Biológicas, são representados na Tabela 1.

Tabela 1: Número e porcentagem de respostas a três questões sobre eutanásia, entre estudantes dos cursos de Medicina Veterinária e Ciências Biológicas, da Universidade Paranaense, 2006

\begin{tabular}{lccc}
\hline & \multicolumn{2}{c}{ Respostas - n (\%; IC95\%) } & \\
\hline Questão: Curso & Desfavoráveis & Favoráveis & Valor de P \\
\hline Q1: eutanásia "piedosa" & & & \\
Ciências Biológicas & $14(13,2 \% ; 8,1-21,0)$ & $92(86,8 \% ; 79,0-91,9)$ & 0,0165 \\
Medicina Veterinária & $2(2,7 \% ; 0,8-9,3)$ & $71(97,3 \% ; 88,8-98,5)$ & \\
\hline Q2: eutanásia "sanitária" & & & \\
Ciências Biológicas & $58(57,4 \% ; 47,7-66,6)$ & $43(42,6 \% ; 33,4-52,3)$ & 0,0001 \\
Medicina Veterinária & $18(25,0 \% ; 16,4-36,1)$ & $54(75,0 \% ; 63,9-83,5)$ & \\
\hline Q3: eutanásia "para manejo" & & & \\
Ciências Biológicas & $75(71,4 \% ; 62,1-79,2)$ & $30(28,6 \% ; 20,8-37,9)$ & 0,0016 \\
Medicina Veterinária & $34(47,2 \% ; 36,1-58,6)$ & $38(52,8 \% ; 41,4-63,9)$ & \\
\hline
\end{tabular}
estudantes dos cursos de Ciências Biológicas e Medicina Veterinária.

Os resultados revelam que os estudantes do curso de Medicina Veterinária mostraram-se sempre mais favoráveis à eutanásia do que os estudantes do curso de Ciências Biológicas, independentemente do tipo de eutanásia estudado.

$\mathrm{Na}$ questão para eutanásia "piedosa", os dois grupos de estudantes pesquisados apresentaram a mesma freqüência de respostas, sendo significativamente favoráveis a essa 
prática. Fica evidente, entretanto, que no caso das eutanásias "sanitária" e "para manejo", a proporção de estudantes do curso de Medicina Veterinária favoráveis a essas práticas foi mais elevada do que do curso de Ciências Biológicas. É importante salientar que os estudantes de Ciências Biológicas foram significativamente desfavoráveis às práticas da eutanásia "sanitária" e "para manejo".

Já nas questões da eutanásia "sanitária" e da eutanásia "para manejo", o comportamento dos dois grupos foi diferente e houve duas situações de indefinição, que se referem à eutanásia "sanitária", entre os estudantes de Ciências Biológicas, e à eutanásia "para manejo" entre os estudantes do curso de Medicina Veterinária. Tal indefinição está representada pelos intervalos de confiança das freqüências entre as respostas favoráveis e desfavoráveis, onde não se observou diferença significativa.

Entendemos que a eutanásia sanitária é necessária, visto que protege a vida comum, enquanto a eutanásia para manejo é condenável, representando falta de planejamento e, portanto, além do sacrifício dos animais, consumo desnecessário de recursos financeiros e naturais. A indefinição dos grupos nestes casos pode dar margem a duas interpretações: a) os estudantes não compreenderam bem a definição dos termos; b) tratava-se de turma muito heterogênea.

As eutanásias "sanitária" e "para manejo" têm enfoque técnico e, neste caso, os estudantes de Medicina Veterinária se mostraram favoráveis à prática, enquanto os de Ciências Biológicas apresentaram-se desfavoráveis. É conveniente salientar que faz parte da formação do médico-veterinário, como agente de saúde pública, ter um enfoque técnico para esta questão, justificando-se então o contraste nas respostas dos dois grupos.

Não está em discussão neste trabalho se é correto ou não promover a eutanásia de animais, mas sim como futuros biólogos e futuros médicos-veterinários encaram esse fato, visto que há divergências de como esses profissionais encaram o fenômeno "vida".

No Código de Ética Profissional do Biólogo destaca-se no artigo 1 que "toda atividade do biólogo deverá sempre consagrar respeito à vida, em todas as suas formas e manifestações, e à qualidade do meio ambiente" e no artigo 2o "o conhecimento, a capacidade e a experiência do biólogo deverão ser instrumento de utilização permanente para ... garantir a manutenção da qualidade de vida dos processos vitais". Não há neste documento nenhuma referência ao fenômeno "morte" (Conselho Federal de Biologia, 2006; grifos nossos).

Já o texto do Código de Ética Profissional do Médico-Veterinário é permeado pelas idéias de saúde animal, saúde pública e o bem para o homem. No juramento do médico-veterinário

\section{Referências}

AVMA Panel on euthanasia. Report of the AVMA panel on euthanasia. J. Am. Vet. Med. Assoc., v. 218, n. 5, p. 669-696, 2001.

AURICCHIO, A. L. R. Potencial da educação ambiental nos zoológicos brasileiros. Publ. Avulsas Inst. Pau Bras. Hist. Nat, São Paulo, n. 1, p. 1-46, 1999.

BRASIL. Ministério da Agricultura, Pecuária e Abastecimento. Aprova o regulamento técnico do Programa Nacional de Controle e Erradicação da Brucelose e Tuberculose Animal. Instrução normativa n. 6, de 12 de destaca-se "em benefício da prevenção e cura de doenças animais tendo como objetivo o homem", e no artigo 6o, dentre os deveres do médico-veterinário, destaca-se "realizar a eutanásia nos casos devidamente justificados, observando princípios básicos de saúde pública, legislação de proteção aos animais e normas do CFMV" (Conselho Federal de Medicina Veterinária, 2002).

Os trechos apresentados dos códigos de ética das profissões revelam que o profissional biólogo apresenta uma obrigação mais geral com o fenômeno vida, enquanto o médicoveterinário, segundo o documento, tem sua atuação voltada para o homem. Enquanto o médico-veterinário tem a morte sempre presente em sua prática, o biólogo, ao se sentir responsável pela defesa da vida, parece não dar atenção à morte, não discutindo suas implicações, considerando esse fenômeno como ponto final de sua atuação.

Em pesquisa realizada com estudantes do último ano de licenciatura de Ciências Biológicas, Neves Jr. (2005) identificou entre os temas mais complexos, do ponto de vista ético, citados por aqueles alunos, a clonagem de seres humanos, a pesquisa com seres humanos e as células-tronco. A eutanásia não está entre os assuntos mais destacados.

\section{Considerações finais}

Verificamos neste trabalho que estudantes de Medicina Veterinária e Ciências Biológicas, na população estudada, apresentam posições diferentes com relação às práticas de eutanásia. Essa diferença refletiu as idéias contidas nos códigos de ética dos profissionais.

Quando a questão é a eutanásia "piedosa", a idéia que prevaleceu foi a favorável, revelando o desconforto que causa na humanidade o sofrimento animal. Porém, com relação às eutanásias "sanitária" e "para manejo", que definimos como técnicas, ocorreu diferença de pensamento entre os dois grupos de alunos avaliados.

A questão ética sobre a morte deve ser privilegiada nos cursos de formação dos profissionais. Biólogos devem "tecnificar sua piedade" e entender as razões de um abate sanitário, em prol da saúde, não apenas humana, mas também do ecossistema. Médicos-veterinários devem "humanizar a sua técnica" e defender a vida animal quando esta não represente ameaça a toda vida do planeta, contribuindo com as decisões sobre o planejamento da produção.

As decisões sobre as condutas e procedimentos que envolvam a vida ou a morte de qualquer organismo, por mais regulamentadas que possam estar, devem ser sempre oportunidades para o exercício de reflexões sobre a nossa existência enquanto ser vivo que compartilha e determina com outras espécies o fenômeno vida.

janeiro de 2004. Lex: Diário Oficial da União, Brasília, DF, seção 1, p. 6 , 12/1/2004.

CONSELHO FEDERAL DE BIOLOGIA. Aprova o código de ética profissional do biólogo. Resolução n. 8, de 12 de junho de 1991. Disponível em <http://www.cfbio.org.br/main_screen.htm>. Acessado em 15 agosto 2006.

CONSELHO FEDERAL DE MEDICINA VETERINÁRIA. Aprova o código de ética do Médico-Veterinário. Resolução n. 722, de 16 de agosto de 2002. Lex: Diário Oficial da União, Brasília, seção 1, p. 162, 16/12/ 2002. 
CONSELHO FEDERAL DE MEDICINA VETERINÁRIA. Dispõe sobre procedimentos e métodos de eutanásia em animais. Resolução n. 714, de 20 de junho de 20 de junho de 2002. Disponível em <http:// www.cfmv.org.br/menu_cfmv/legislacao/resolucoes/ resolucao_714.htm. Acessado em 15 agosto 2006.

CURI, P. R. Metodologia e análise da pesquisa em Ciências Biológicas. 2. ed. Botucatu: Tipomic, 1998. 263 p.

FRANCO, C. B.; SEMINOTTI, N. A relação homem-natureza e a prática veterinária. Revista CFMV, n. 32, p. 57-61, 2004.
HOUAISS, A. Dicionário eletrônico Houaiss da língua portuguesa. Rio de Janeiro. 2002. CD-ROM.

MOLENTO, C. F. M. Medicina veterinária e bem-estar animal. Revista CFMV, n. 28/29, p. 15-20, 2003.

NEVES Jr., W. A. Os temas de bioética que os estudantes de biologia consideram mais complexos do ponto de vista ético. In CONGRESSO BRASILEIRO DE BIOÉTICA, 6., Foz do Iguaçu. Anais.., 2005. p. 245 (Resumo). 